\title{
Differential Age-Related Bone Architecture Changes between Female and Male STR/Ort Mice
}

\author{
Kentaro UCHIDA ${ }^{1)}$, Ken URABE ${ }^{1)}$, Kouji NARUSE ${ }^{1)}$, Yusuke KOZAI ${ }^{2)}$, Kenji ONUMA ${ }^{1)}$, \\ Yuko MIKUNI-TAKAGAKI ${ }^{3)}$, Isamu KASHIMA ${ }^{2)}$, Masaki UENO ${ }^{1)}$, Rina SAKAI ${ }^{4}$, \\ Moritoshi ITOMAN ${ }^{5}$, and Masashi TAKASO ${ }^{1)}$
}

\footnotetext{
${ }^{1)}$ Department of Orthopedic Surgery, Kitasato University School of Medicine, 1-15-1 Kitasato, Minami-ku, Sagamihara, Kanagawa 252-0374, ${ }^{2}$ Department of Maxillofacial Diagnostic Science, Kanagawa Dental College, 82 Inaokacho, Yokosuka, Kanagawa 238-8580, ${ }^{3)}$ Department of Functional Biology, Kanagawa Dental College, 82 Inaokacho, Yokosuka, Kanagawa 238-8580,

${ }^{4)}$ Department of Medical Engineering and Technology, School of Allied Health Science, Kitasato University, 1-15-1 Minami-ku Kitasato, Sagamihara, Kanagawa 252-0374, and

${ }^{5)}$ Director of Kyushu Rosai Hospital, 1-3-1 Kuzuharatakamatsu, Kokuraminami-ku, Kitakyushu, Fukuoka 800-0296, Japan
}

\begin{abstract}
The incidence of spontaneous osteoarthritis (OA) in female STR/Ort mice is much lower than that observed in male STR/Ort mice; however, the reason for the differential incidence of OA between sexes has not been elucidated. Here, we investigated and compared age- and sex-related bone mineral density and architectural changes in male and female STR/ Ort mice. Bone architecture and bone mineral density (BMD) of femurs were examined in 5-, 10-, 15-, 20-, and 35-week-old male and female STR/Ort mice by microscopic computed tomography $(\mu \mathrm{CT})$. Angular degrees of internal tibial torsion (ADITT) were also measured in mice at 5,15 , and 35 weeks of age. Earlier decreases of cancellous volume and BMD were found in male STR/Ort mice. Using $\mu \mathrm{CT}$, an age-related decline of bone marrow space in femoral diaphysis was observed in both males and females but was more dramatic in females. In addition, an earlier increase of ADITT was observed in male STR/Ort mice, suggesting that internal rotation of the tibia may contribute to OA. Age- and sex-related bone architectural changes clearly differ between male and female STR/Ort mice. These differences in bone structure, particularly ADITT, may explain the differential incidence of OA in STR/Ort mice.
\end{abstract}

Key words: bone architecture, osteoarthritis, STR/Ort

\section{Introduction}

Male STR/Ort mice, which were initially derived from the parent strain STR/1N following a period of noninbreeding [23], are used as a spontaneous osteoarthritis (OA) model [20, 22,28]. Interestingly, the incidence of
OA in female STR/Ort mice is markedly lower than that in males $[15,28]$, which is opposite to the situation in humans. As the cause of the differential incidence of OA between males and females has not been elucidated, examining OA progression in STR/Ort mice may help reveal the mechanisms responsible for these sex-related

(Received 15 June 2011 / Accepted 15 September 2011)

Address corresponding: K. Uchida, Department of Orthopedic Surgery, Kitasato University School of Medicine, 1-15-1 Kitasato, Minami-ku, Sagamihara, Kanagawa 252-0374, Japan

(C) 2012 Japanese Association for Laboratory Animal Science 
differences.

Age- and sex-related bone changes are often associated with severe musculoskeletal diseases, including OA and osteoporosis. Studies examining the relationships between age-related bone changes and OA development have revealed that elderly patients with OA of knees or hips were more likely to have a higher bone mass and bone mineral density (BMD) compared with healthy individuals of similar age $[9,13,21]$. Higher BMD has also been detected in animal models of OA compared with healthy age-matched controls [5, 14, 22]. Beuf et al. [2] reported that femoral trabecular bone loss was observed in knee OA patients, suggesting that altered bone metabolism and/or architecture is important not only for the development of OA, but also for its progression.

Varus, valgus, and other axial deformities are frequently observed in human OA of the knee joint. In clinical practice, adduction of the foot in a patient standing with the patella faced directly anterior is a result of torsional deformity and is referred to as internal tibial torsion (ITT). Torsional abnormalities are considered by numerous researchers to be either a possible cause or effect of OA [3, 10, 11, 16, 25, 32]. Recently, we found that osteoarthritic changes in the patellofemoral joint in STR/Ort mice may be the result of increasing ITT with aging [20]. Therefore, examining age- and sex-related bone changes in STR/Ort mice may provide useful information for understanding the relationship between OA and bone metabolism.

Here, we investigated and compared bone mineral density and architectural changes in male and female STR/Ort mice from 5 to 35 weeks of age.

\section{Materials and Methods}

\section{Animals}

All procedures involving the handling of animals were in accordance with the guidelines of the animal ethics committee of Kitasato University. An SPF colony of male and female STR/Ort mice was maintained at Charles River Laboratories Japan (Kanagawa, Japan). The mice were housed in a semibarrier system with a controlled environment $\left(23 \pm 2{ }^{\circ} \mathrm{C}, 55 \pm 10 \%\right.$ humidity, and a 12 -h light/dark cycle) throughout the study. All mice were fed a diet of standard rodent chow (CRF-1, Oriental Yeast Co., Ltd., Tokyo, Japan). At 5, 10, 15, 20, and 35 weeks of age, mice were sacrificed by deep anesthesia with diethyl ether. At the time of death, mice were weighed, and radiographic OA was evaluated using soft $\mathrm{X}$-rays. Femurs were then dissected and cleaned of soft tissue. Right femurs were stored in $70 \%$ ethanol for peripheral quantitative computed tomography (pQCT), and left femurs were stored in $4 \%$ paraformaldehyde until microscopic computed tomography $(\mu \mathrm{CT})$ analysis.

\section{Radiographic analysis}

Radiographs of knee joints (lateral projections) were taken at 15 and 35 weeks using a Softex-CMB4 X-ray system (Softex Co., Ltd., Kanagawa, Japan) at $25 \mathrm{kV}$ and $10 \mathrm{~mA}$ and IX Industrial X-Ray Film (Fujifilm Corporation, Tokyo, Japan) with a 10-s exposure time. OA changes on soft $\mathrm{X}$-ray radiographs were evaluated using standard criteria consisting of six abnormal parameters, as previously described [20].

\section{Peripheral quantitative computed tomography ( $p Q C T$ )}

The distal metaphysis (1.4 mm proximal to the growth plate) and mid-diaphysis of excised femurs $(5 \mathrm{~mm}$ proximal to the midpoint) were scanned using an XCT Research SA + pQCT instrument (Stratec Medizintechnik GmbH, Pforzheim, Germany) with a tube voltage and current of $50 \mathrm{kV}$ and $550 \mu \mathrm{A}$, respectively, and a voxel size of $80 \times 80 \times 46 \mu \mathrm{m}$. Cortical bone was defined as areas of BMD $>690 \mathrm{mg} / \mathrm{mm}^{3}$, while a threshold value of $395 \mathrm{mg} / \mathrm{mm}^{3}$ in contour mode 1 was set to define trabecular bone in the bone marrow. Cancellous and cortical BMD $\left(\mathrm{mg} / \mathrm{cm}^{3}\right)$ were then calculated as previously described [19].

\section{Microscopic computed tomography $(\mu C T)$}

$\mu \mathrm{CT}$ (inspeXio SMX-90CT, Shimadzu Corporation, Tokyo, Japan) was used to assess trabecular bone morphology in the distal femoral metaphysis and femoral diaphysis using a $12-\mu \mathrm{m}$ isotropic voxel size, as previously described [12]. We assessed the trabecular bone volume per total tissue volume (BV/TV, \%), trabecular thickness (Tb.Th, $\mu \mathrm{m}$ ), and trabecular number (Tb.N, $\mathrm{mm}^{-1}$ ) of cancellous bone. In addition, we determined 
the cortical bone volume per total tissue volume (cBV/ $\mathrm{TV}, \%$ ), external line length (ELL, $\mu \mathrm{m}$ ), and medullary volume $\left(\mathrm{MV}, \mathrm{mm}^{3}\right)$ of cortical bone. As age- and sexspecific patterns of bone architectural changes were nearly identical between the tibia and femur of STR/Ort mice, we selected to report data for only the femur.

\section{Ovariectomy}

Female STR/Ort mice at 10 or 16 weeks of age were divided into two groups $(n=8)$, which received bilateral ovariectomies or sham operations, respectively. Six weeks after surgery, femurs were harvested and stored in $4 \%$ paraformaldehyde or $70 \%$ ethanol until they were subjected to $\mu \mathrm{CT}$ or pQCT analysis.

\section{Measurement of the angular degree of ITT (ADITT)}

ADITT was determined by superimposing the proximal tibial posterior condylar axis onto the distal bimalleolar axis using $\mu \mathrm{CT}$ images [20]. The tibial posterior condylar axis was defined as the line connecting the two most posterior points of the medial and lateral condyle of the tibia at the joint surface level. The bimalleolar axis was defined as the line connecting the medial malleolus and lateral malleolus of the ankle.

\section{Statistical analysis}

All statistical analyses were performed using SPSS software (Version 11.0; SPSS, Inc., Chicago, IL, USA). One-way ANOVA with Tukey's multiple comparison test was used to examine differences between sex-matched mice. An unpaired $t$-test was used to examine differences between age-matched male and female mice. A $P$ value of $<0.05$ was considered statistically significant.

\section{Results}

\section{Incidence of radiographic $O A$}

Radiographic OA changes at 15 weeks were not detected for either male or female STR/Ort mice (Fig. 1A and 1C). Joint space narrowing, subchondral bone sclerosis, and osteophyte formation were noted in males at 35 weeks (Fig. 1B). At 35 weeks, osteoarthritic changes were observed in $80 \%$ of male STR/Ort mice (Table 1). However, no osteoarthritic changes were found in females at 35 weeks (Fig. 1D).
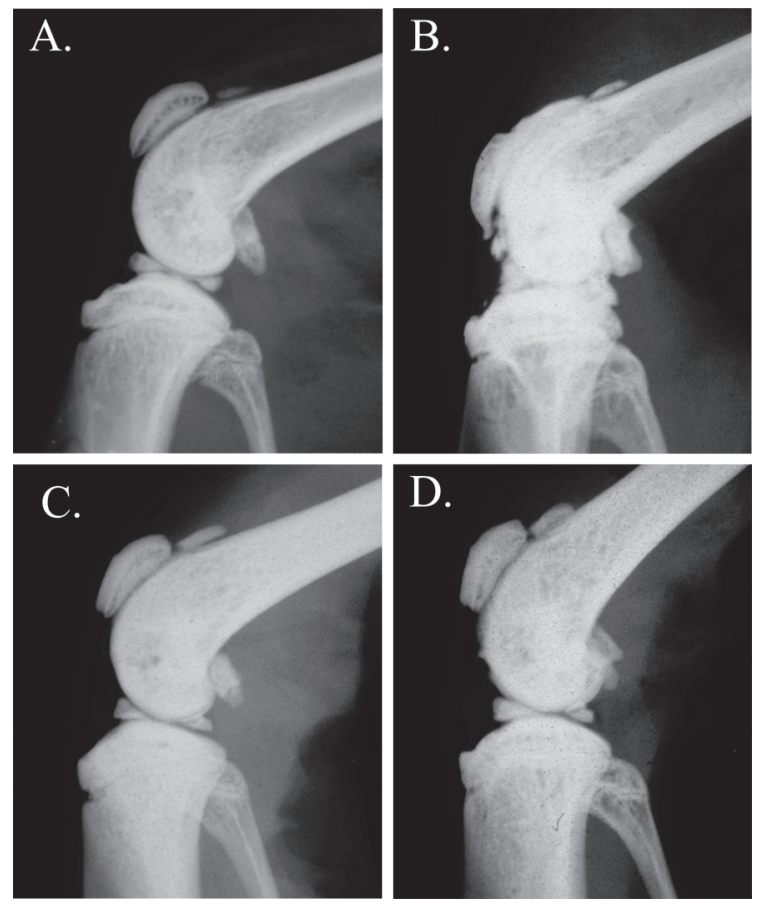

Fig. 1. Typical radiographs of the lateral projections of the knees of STR/Ort mice at 15 and 35 weeks of age $(n=20)$. A. Male STR/Ort mouse at 15 weeks. B. Male STR/Ort mouse at 35 weeks. C. Female STR/Ort mouse at 15 weeks. D. Female STR/Ort mouse at 35 weeks.

Table 1. Incidence of radiographic osteoarthritis in STR/Ort mice $(\mathrm{n}=10)$

\begin{tabular}{lcc}
\hline & \multicolumn{2}{c}{ Age (weeks) } \\
\cline { 2 - 3 } & 15 & 35 \\
\hline Male & $0 / 10$ & $8 / 10$ \\
Female & $0 / 10$ & $0 / 10$ \\
\hline
\end{tabular}

Age-related changes in cancellous and cortical BMD of femurs

We first examined changes in the density of cancellous and cortical bone in the femurs of STR/Ort mice between 5 and 35 weeks of age (Fig. 2). Femoral cancellous BMD increased between 5 and 10 weeks of age and declined thereafter in male mice but increased until 20 weeks of age in females and then exhibited a relatively rapid decline (Fig. 2A). ANOVA revealed a significant age-bysex interaction, indicating that patterns of age-related changes in cancellous BMD differed in male and female STR/Ort mice. Between 15 and 20 weeks of age, cancel- 
A

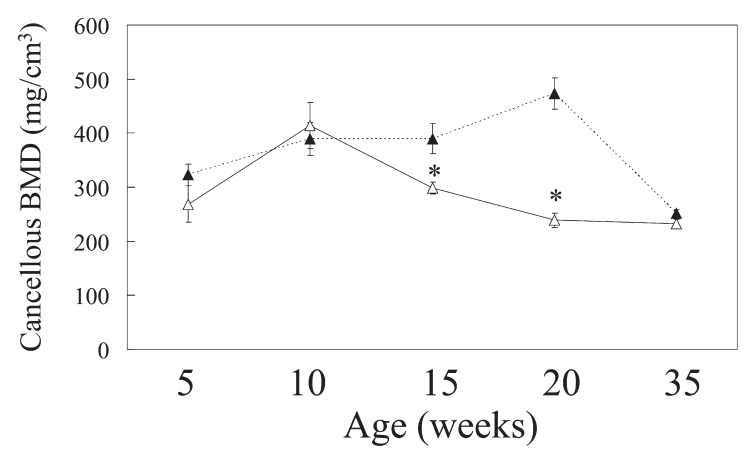

B

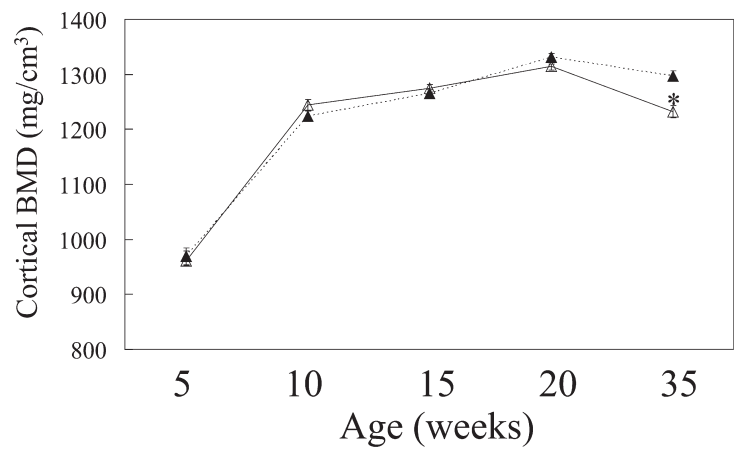

Fig. 2. Age-related changes in cancellous and cortical bone marrow density (BMD) in the femurs of male (open triangles) and female (closed triangles) STR/Ort mice $(n=10)$. A. Cancellous BMD in the femoral metaphysis. B. Cortical BMD in the femoral diaphysis. Values are presented as means \pm SE. The asterisks $(*)$ indicate significant differences at $P<0.05$ compared with age-matched female mice.

lous BMD in females was markedly higher than that in males. In contrast, cortical BMD in the femoral diaphysis displayed nearly identical increases between 5 and 10 weeks of age in both males and females and remained stable until 35 weeks of age (Fig. 2B). No significant age-related changes were detected between males and females.

Age-related changes in trabecular bone architecture by $\mu C T$

In female STR/Ort mice, no significant changes in femoral BV/TV were observed until 15 weeks of age, at which point $\mathrm{BV} / \mathrm{TV}$ drastically increased until 35 weeks of age (Fig. 3A). In males, BV/TV decreased at 10 weeks of age and was then relatively stable until 35 weeks of age. ANOVA revealed a significant age-by-sex interaction among adults, indicating that patterns of agerelated change in trabecular bone architecture differed in males and females. Specifically, trabecular BV/TV in females at 10,20, and 35 weeks of age were significantly higher than that in males.

Tb.N in females showed a pattern similar to that of $\mathrm{BV} / \mathrm{TV}$, increasing between 15 and 20 weeks of age, with higher values detected at 10,20, and 35 weeks of age than those in males (Fig. 3B). Tb.Th was also significantly higher in females than males at 20 and 35 weeks of age (Fig. 3C). In addition, age-related changes in trabecular architecture at the proximal tibia followed patterns similar to those of the distal femur (data not

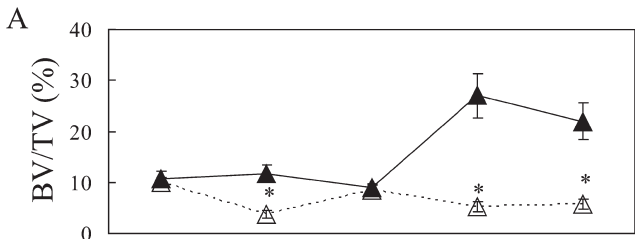

B

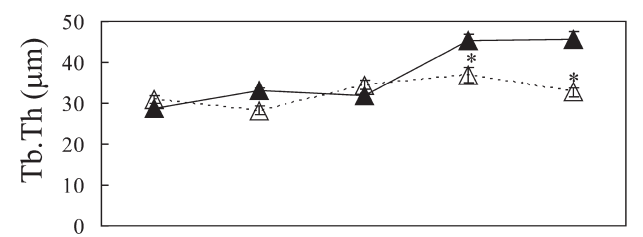

$\mathrm{C}$

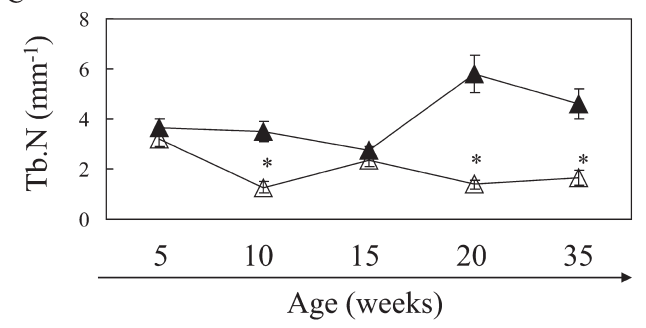

Fig. 3. Age-related changes in cancellous bone architecture in the femurs of male (open triangles) and female (closed triangles) STR/ Ort mice $(n=10)$. A. BV/TV. B. Tb.th. C. Tb.N. Values are presented as means $\pm \mathrm{SE}$. The asterisks (*) indicate significant differences at $P<0.05$ compared with age-matched female mice.

shown). To estimate the effect of bone structural differences (tibial torsional angle), data for the distal femur was evaluated. 
A

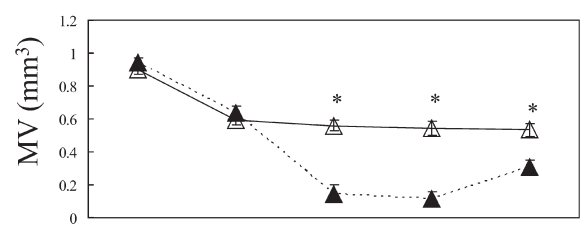

B

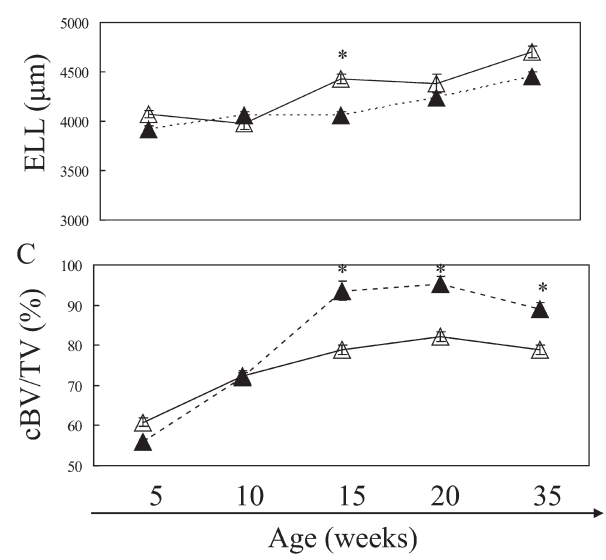

Fig. 4. Age-related changes in cortical bone architecture in the femurs of male (open triangles) and female (closed triangles) STR/Ort mice $(n=10)$. A. Marrow volume. B. External line length. C. Cortical $\mathrm{BV} / \mathrm{TV}(\mathrm{cBV} / \mathrm{TV})$. Values are presented as means $\pm \mathrm{SE}$. The asterisks (*) indicate significant differences at $P<0.05$ compared with age-matched female mice.

Age-related cortical bone changes in the femoral diaphysis by $\mu C T$

To evaluate potential concomitant changes in cortical architecture, we next assessed the cortical bone morphology in the femoral diaphysis of STR/Ort mice between 5 and 35 weeks of age (Fig. 4). At the femoral diaphysis, MV in females decreased dramatically from 10 to 15 weeks of age and was significantly lower than that of males at 15, 20, and 35 weeks of age (Fig. 4A). ELL increased with aging (Fig. 4B). Although ELL in 15 -week-old males was higher than that in age-matched females, no differences were observed in mice of any other ages examined. However, cBV/TV in females increased dramatically from 10 to 15 weeks of age and was significantly higher than that of males at 15,20 , and 35 weeks of age (Fig. 4C).
Table 2. Age- and sex-related changes in the angular degree of internal tibial torsion (ADITT) in STR/Ort mice

\begin{tabular}{lccc}
\hline & \multicolumn{3}{c}{ Age (weeks) } \\
& 5 & 15 & 35 \\
\hline Male & $-2.0 \pm 1.1$ & $7.1 \pm 1.1^{\mathrm{a}, \mathrm{b})}$ & $7.1 \pm 1.0^{\mathrm{a}, \mathrm{b})}$ \\
Female & $-3.2 \pm 1.0$ & $-3.0 \pm 0.6$ & $1.9 \pm 0.9^{\mathrm{a})}$ \\
\hline
\end{tabular}

ADITT data are presented as means $\pm \operatorname{SE}(\mathrm{n}=20) .{ }^{\text {a) }}: P<0.05$ compared with sex-matched 5-week-old mice. ${ }^{\text {b) }}: P<0.05$ compared with age-matched female mice.

Age-related changes in ADITT

Changes of ADITT with aging were examined in 5-, 15-, and 35-week-old STR/Ort mice (Table 2). ADITT of female STR/Ort mice at 35 weeks of age was higher than that in 5- and 15-week-old females. In male STR/ Ort mice, ADITT increased with age and was significantly higher in 15- and 35-week-old males than that in 5-week-old males. Sex-based differences were also detected, as the ADITTs of male STR/Ort mice at 15 and 35 weeks of age were significantly higher than those of age-matched female mice.

\section{Effect of ovariectomy on bone architecture}

To investigate the involvement of osteoclasts in bone marrow narrowing in female mice, ovariectomies were performed in 10-week-old female STR/Ort mice with confirmed narrow bone marrow space. The MVs of these ovariectomized (OVX) mice significantly increased, whereas $\mathrm{cBV} / \mathrm{TV}$ and BMD significantly decreased (Fig. $5 \mathrm{~A}, 5 \mathrm{C}$, and 5D, respectively). No differences in external line length were found between the sham-operated and OVX groups (Fig. 5B). Ovariectomies were also performed in 15-week-old female STR/Ort mice, in which the bone marrow space had disappeared, and significant increases in MV and decreased BMD were also observed (Fig. 5A, 5C, and 5D, respectively).

\section{Discussion}

In this study, we examined differences in BMD and bone architectural changes with aging between male and female STR/Ort mice. Earlier decreases of cancellous BMD were observed in male STR/Ort mice, while no differences in cortical BMD were detected between males and females. An age-related decline in the bone 


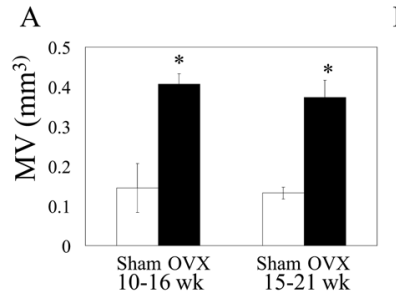

B

$\mathrm{C}$
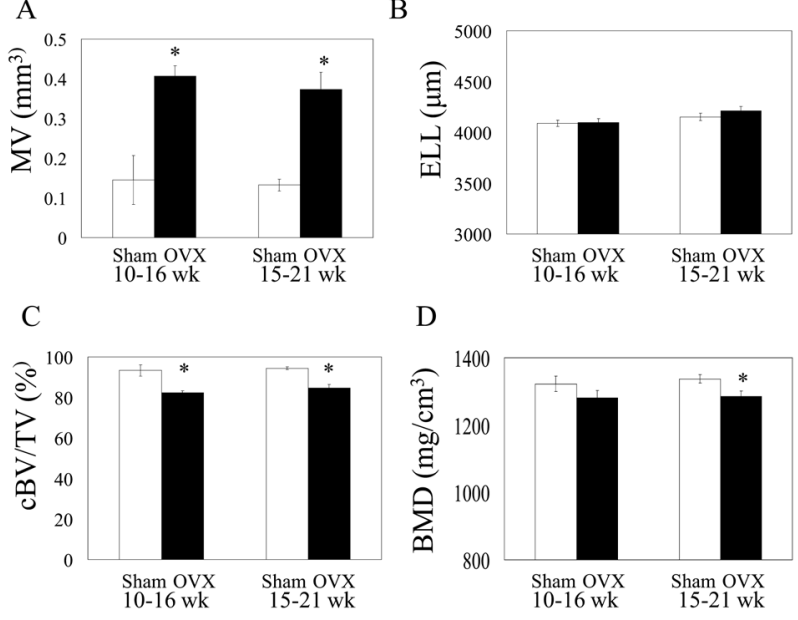

D

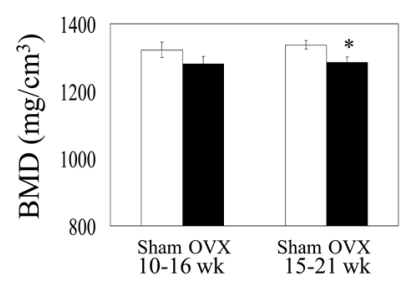

Fig. 5. Effect of ovariectomy on cortical bone architecture of female STR/Ort mice $(n=8)$. A. Cortical bone marrow volume. B. External line length. C. Cortical BV/TV (cBV/TV). D. Bone marrow density (BMD). Values are presented as means $\pm \mathrm{SE}$. The asterisks $(*)$ indicate significant differences at $P<0.05$ compared with sham-operated mice.

marrow space of the femoral diaphysis occurred in both males and females but was more dramatic in female mice. In addition, an earlier increase in ADITT was observed in male STR/Ort mice. Diffrences in age- and sex-related bone architecture changes between female and male STR/Ort mice may explain the differential incidence of OA observed in STR/Ort mice.

In humans, subchondral bone changes are important in the progression of OA, while in small animals, femoral shaft BMD also influences OA progressions [5, 14, $22]$. For example, a comparative analysis of bone and cartilage metabolism in Hartley guinea pigs with naturally occurring OA showed that femoral shaft BMD was higher in guinea pigs with OA than in controls [14]. Calvo et al. [5] demonstrated that lower BMD increased the severity of cartilage damage in an experimental model of knee OA in rabbits, while Sarukawa et al. [22] reported that an increase in femoral BMD prior to the establishment of radiographic OA in male STR/Ort mice may be related to the development of OA. In the present study, no differences in the BMD of the femoral diaphysis were detected between male and female STR/Ort mice. Therefore, the BMD of the femoral diaphysis does not appear related to the differential incidence of OA between males and females.

In addition to subchondral and femoral shaft BMD changes, modifications to cancellous bone have also been reported in OA patients and model animals $[2,8,9,17]$. In a guinea pig OA model, Layton et al. [17] observed with $\mu \mathrm{CT}$ that an initial bone loss of trabecular volume fraction led to initiation of OA. In a canine OA model induced by anterior cruciate ligament (ACL) transection, Dedrick et al. [7] demonstrated than an increase in subchondral bone thickness was accompanied by a decrease in trabecular thickness, while Beuf et al. [2] reported that a reduction in $\mathrm{BV} / \mathrm{TV}$ was observed in human knee OA patients. Here, we found that decreasing cancellous volume and BMD occurred earlier in male STR/Ort mice than in females, a result which may explain the earlier initiation and progression of OA in male STR/Ort mice.

Several studies have reported that increased bone resorption occurs in OA patients $[1,18]$. In our present study, in addition to differences of cancellous volume and $\mathrm{BMD}$, we found that the bone marrow space in female STR/Ort mice decreased with age and had nearly completely disappeared by 15 weeks of age. Therefore, we speculated that lower bone resorption is a characteristic phenotype of female STR/Ort mice. To investigate the effects of bone resorption in differential bone structure changes, we accelerated bone resorption using ovariectomy. Acceleration of osteoclastogenesis by ovariectomy significantly increased the bone marrow space, even when ovariectomy was performed at 15 weeks of age, at which time the bone marrow space had nearly entirely disappeared. Recently, peroxisome proliferatoractivated receptor- $\gamma$ (PPAR- $\gamma$ ) signaling, which plays an important role for pro-osteoclastogenic differentiation [29], was shown to be downregulated in male STR/Ort mice [30]. Tie2Cre-mediated hematopoietic cell-specific PPAR- $\gamma$ deletion leads to osteopetrosis, which is characterized by markedly increased bone volume and a reduced medullary cavity space in Tb.th and Tb.N. Our observed changes in female STR/Ort mice were remarkably similar to those found in Tie2Cre-mediated PPAR- $\gamma$ knockout mice [29]. Osteopetrosis occurs when the rate of bone formation exceeds the rate of bone resorption. Our findings suggest that the lower rate of bone resorption in female STR/Ort may have participated in osteo- 
petrotic changes.

In contrast, bone marrow narrowing in male STR/Ort mice was relatively minimal. Notably, patella dislocation increased with age in male, but not female, STR/ Ort mice [28]. Our preliminary data suggest that surgical patella dislocation in normal rats induces cancellous and cortical bone loss and an increase of endosteal circumference; therefore, differential bone architectural changes may be associated with patella dislocation in male STR/Ort mice. Taken together with the findings of Masell et al. [18], who reported that hip OA cancellous bone has markedly higher bone metabolism activity compared with normal tissues, and Bettica et al. [1], who observed increased bone resorption in patients with progressive knee OA, our results suggest that sex-related differences in bone resorption activity contribute to the different incidence of OA in STR/Ort mice.

Prior to our present study, we speculated that male STR/Ort mice may have higher bone resorption than females. However, although acceleration of bone resorpiton by ovariectomy changed the bone structure in female mice, the incidence of OA was not affected, a finding that is consistent with previous reports [6]. Therefore, we propose that other factors may contribute to OA progression in male STR/Ort mice. We also previously reported that osteoarthritic changes in male STR/Ort mice may be caused by ITT [20]. Turner [24] identified that the knees of OA patients with patellofemoral instability had greater external tibial torsion than normal subjects, whereas patients with panarticular OA of the knee exhibited reduced external torsion or true internal torsion. In addition, Yagi et al. [31, 32] reported the occurrence of tibial torsional deformities in association with medial-type osteoarthritic knees. Here, the internal rotation of the tibia markedly increased with age in male STR/Ort mice. Taken together, these results suggest that increased ITT contributes to OA in male STR/Ort mice.

A few limitations of the study warrant mention. A primary shortcoming of our study is that we inferred age-related changes by cross-sectional analysis. In future studies, the use of in vivo $\mu \mathrm{CT}$ systems will facilitate longitudinal assessment of changes in bone architecture with aging $[4,26,27]$. In addition, we only examined age-related bone changes, and relationships between $\mathrm{OA}$ initiation and/or progression were not investigated.

In conclusion, age- and sex-related bone architectural changes differ between male and female STR/Ort mice. These differences in bone structure may explain the differential incidence of OA observed in STR/Ort mice.

\section{References}

1. Bettica, P., Cline, G., Hart, D.J., Meyer, J., and Spector, T.D. 2002. Evidence for increased bone resorption in patients with progressive knee osteoarthritis: longitudinal results from the Chingford study. Arthritis Rheum. 46: 31783184 .

2. Beuf, O., Ghosh, S., Newitt, D.C., Link, T.M., Steinbach, L., Ries, M., Lane, N., and Majumdar, S. 2002. Magnetic resonance imaging of normal and osteoarthritic trabecular bone structure in the human knee. Arthritis Rheum. 46: 385-393.

3. Blaimont, P. and Schoon, R. 1977. [2 cases of gonarthrosis associated with an internal torsion abnormality of the tibia]. Acta Orthop. Belg. 43: 476-481 (in French).

4. Boyd, S.K., Davison, P., Muller, R., and Gasser, J.A. 2006. Monitoring individual morphological changes over time in ovariectomized rats by in vivo micro-computed tomography. Bone 39: 854-862.

5. Calvo, E., Castaneda, S., Largo, R., Fernandez-Valle, M.E., Rodriguez-Salvanes, F., and Herrero-Beaumont, G. 2007. Osteoporosis increases the severity of cartilage damage in an experimental model of osteoarthritis in rabbits. Osteoarthritis. Cartilage. 15: 69-77.

6. Chambers, M.G., Cox, L., Chong, L., Suri, N., Cover, P., Bayliss, M.T., and Mason, R.M. 2001. Matrix metalloproteinases and aggrecanases cleave aggrecan in different zones of normal cartilage but colocalize in the development of osteoarthritic lesions in STR/ort mice. Arthritis Rheum. 44: 1455-1465.

7. Dedrick, D.K., Goldstein, S.A., Brandt, K.D., O'Connor, B.L., Goulet, R.W., and Albrecht, M. 1993. A longitudinal study of subchondral plate and trabecular bone in cruciatedeficient dogs with osteoarthritis followed up for 54 months. Arthritis Rheum. 36: 1460-1467.

8. Dedrick, D.K., Goulet, R., Huston, L., Goldstein, S.A., and Bole, G.G. 1991. Early bone changes in experimental osteoarthritis using microscopic computed tomography. $J$. Rheumatol. Suppl 27: 44-45.

9. Dequeker, J., Mokassa, L., and Aerssens, J. 1995. Bone density and osteoarthritis. J. Rheumatol. Suppl 43: 98100.

10. Ficat, P. 1977. [Disorders of the patellar gliding balance]. Chir Narzadow. Ruchu. Ortop. Pol. 42: 169-176 (in Polish).

11. Fox, T.A. 1975. Dysplasia of the quadriceps mechanism: hypoplasia of the vastus medialis muscle as related to the hypermobile patella syndrome. Surg. Clin. North Am. 55: 199-226.

12. Glatt, V., Canalis, E., Stadmeyer, L., and Bouxsein, M.L. 
2007. Age-related changes in trabecular architecture differ in female and male C57BL/6J mice. J.Bone Miner. Res. 22: 1197-1207.

13. Hart, D.J., Mootoosamy, I., Doyle, D.V., and Spector, T.D. 1994. The relationship between osteoarthritis and osteoporosis in the general population: the Chingford Study. Ann. Rheum. Dis. 53: 158-162.

14. Huebner, J.L., Hanes, M.A., Beekman, B., TeKoppele, J.M., and Kraus, V.B. 2002. A comparative analysis of bone and cartilage metabolism in two strains of guinea-pig with varying degrees of naturally occurring osteoarthritis. Osteoarthritis. Cartilage. 10: 758-767.

15. Jay, G.E. Jr. and Sokoloff, L. 1956. Natural history of degenerative joint disease in small laboratory animals. II. Epiphyseal maturation and osteoarthritis of the knee of mice of inbred strains. AMA. Arch. Pathol. 62: 129-135.

16. Larson, R.L., Cabaud, H.E., Slocum, D.B., James, S.L., Keenan, T., and Hutchinson, T. 1978. The patellar compression syndrome: surgical treatment by lateral retinacular release. Clin. Orthop. Relat Res. (34): 158167.

17. Layton, M.W., Goldstein, S.A., Goulet, R.W., Feldkamp, L.A., Kubinski, D.J., and Bole, G.G. 1988. Examination of subchondral bone architecture in experimental osteoarthritis by microscopic computed axial tomography. Arthritis Rheum. 31: 1400-1405.

18. Mansell, J.P. and Bailey, A.J. 1998. Abnormal cancellous bone collagen metabolism in osteoarthritis. J. Clin. Invest. 101: 1596-1603.

19. Matsumoto, Y., Mikuni-Takagaki, Y., Kozai, Y., Miyagawa, K., Naruse, K., Wakao, H., Kawamata, R., Kashima, I., and Sakurai, T. 2009. Prior treatment with vitamin K(2) significantly improves the efficacy of risedronate. Osteoporos. Int. 20: 1863-1872.

20. Naruse, K., Urabe, K., Jiang, S.X., Uchida, K., Kozai, Y., Minehara, H., Mikuni-Takagaki, Y., Kashima, I., and Itoman, M. 2009. Osteoarthritic changes of the patellofemoral joint in STR/OrtCrlj mice are the earliest detectable changes and may be caused by internal tibial torsion. Connect. Tissue Res. 50: 243-255.

21. Nevitt, M.C., Lane, N.E., Scott, J.C., Hochberg, M.C., Pressman, A.R., Genant, H.K., and Cummings, S.R. 1995. Radiographic osteoarthritis of the hip and bone mineral density. The Study of Osteoporotic Fractures Research Group. Arthritis Rheum. 38: 907-916.

22. Sarukawa, J., Takahashi, M., Doi, M., Suzuki, D., and Nagano, A. 2010. A longitudinal analysis of urinary biochemical markers and bone mineral density in STR/Ort mice as a model of spontaneous osteoarthritis. Arthritis Rheum. 62: 463-471.

23. Schunke, M., Tillmann, B., Bruck, M., and Muller-Ruchholtz, W. 1988. Morphologic characteristics of developing osteoarthrotic lesions in the knee cartilage of STR/IN mice. Arthritis Rheum. 31: 898-905.

24. Turner, M.S. 1994. The association between tibial torsion and knee joint pathology. Clin. Orthop. Relat Res. 47-51.

25. Turner, M.S. and Smillie, I.S. 1981. The effect of tibial torsion of the pathology of the knee. J. Bone Joint Surg. Br. 63-B: 396-398.

26. Waarsing, J.H., Day, J.S., van der Linden, J.C., Ederveen, A.G., Spanjers, C., De, C.N., Sasov, A., Verhaar, J.A., and Weinans, H. 2004. Detecting and tracking local changes in the tibiae of individual rats: a novel method to analyse longitudinal in vivo micro-CT data. Bone 34: 163-169.

27. Waarsing, J.H., Day, J.S., Verhaar, J.A., Ederveen, A.G., and Weinans, H. 2006. Bone loss dynamics result in trabecular alignment in aging and ovariectomized rats. J. Orthop. Res. 24: 926-935.

28. Walton, M. 1977. Degenerative joint disease in the mouse knee; radiological and morphological observations. $J$. Pathol. 123: 97-107.

29. Wan, Y., Chong, L.W., and Evans, R.M. 2007. PPAR-gamma regulates osteoclastogenesis in mice. Nat. Med. 13: 14961503.

30. Watters, J.W., Cheng, C., Pickarski, M., Wesolowski, G.A., Zhuo, Y., Hayami, T., Wang, W., Szumiloski, J., Phillips, R.L., and Duong, 1.T. 2007. Inverse relationship between matrix remodeling and lipid metabolism during osteoarthritis progression in the STR/Ort mouse. Arthritis Rheum. 56: 2999-3009.

31. Yagi, T. 1994. Tibial torsion in patients with medial-type osteoarthrotic knees. Clin. Orthop. Relat Res. (302): 5256.

32. Yagi, T. and Sasaki, T. 1986. Tibial torsion in patients with medial-type osteoarthritic knee. Clin. Orthop. Relat Res. (213): 177-182. 